\title{
Reseñas
}

\section{Heller, Patrick, The Labor of Development. Workers and the Transformation of Capitalism in Kerala, India, Ithaca, Cornell University Press, 1999}

\section{Silvia E. G iorguli Saucedo*}

El Estado desarrollista democrático necesitará tener un amplio mandato con al men os tres funcion es soci oecon ómicas: regula dora, deinfra estructu ra y redistributiva. También necesitará la suficiente autoridad política y la capacidad administrativa para manejar los conflictos sociales y políticos que surjan por la persistencia de los "lazos primordiales" y de la tensión inherente a un proceso de crecimiento exitoso [White citado en Heller, 1999: 35].

El cambio de gobierno en México y la redefinición de nuestro camino hacia el "desarrollo" se están dando en un marco de discusión más amplio acerca de la responsabilidad del Estado y de la sociedad en la búsqueda del desarrollo. Los ejemplos más citados por los políticos y economistas mexicanos suelen ser los casos de los países del sudeste asiático, Japón y Chile. Sabemos poco de las experiencias de aquellos que han tomado caminos diferentes, y han combinado la inserción al mercado con la priorización de los procesos democratizadores, la participación social y una distribución más equitativa de los costos y beneficios del desarrollo.

El estado de Kerala, en India, es un caso conocido y citado frecuentemente en la literatura como un ejemplo exitoso de desarrollo social. Sus indicadores sociales son inusualmente elevados en comparación con sus indicadores económicos. En la época de la independencia de la India - a mediados del siglo xx - Kerala era el estado más pobre de dicho país. Ahora, a pesar de que el ingreso sigue estando por debajo del promedio en India, Kerala tiene los mejores indicadores de salud, educación y niveles de vida de todo el país. Junto con Costa Rica y Sri Lanka, Kerala representa un reto para las visiones generales de los caminos hacia el desarrollo. El caso de Kerala

* Profesora-investigadora del Centro de Estudios Demograficos y de Desarrollo Urbano de El Colegio de México. Correo electrónico: sgiorgeli@colmex.mx. La autora de la reseña agradece especialmente los comentarios de Dietrich Rueschemeyer. 
refuta la idea de que es imposible lograr un desarrollo social sostenido si antes no se prioriza el crecimiento económico a costa de la distribución del ingreso. Rebate la suposición de que la participación, las movilizaciones sociales y los procesos democráticos deben someterse a las necesidades de las políticas de crecimiento económico. Finalmente, impugna la noción de la supuesta incompatibilidad entre crecimiento económico y desarrollo social paralelos.

¿En qué se basa el éxito de Kerala al promover el desarrollo social en un contexto tan desfavorable (con recursos tan escasos, pobreza extendida y una visible desigualdad social basada en el sistema de castas)? La respuesta de Patrick Heller en su libro The Labor of Development. Workers and the Transformation of Capitalism in Kerala es que allí el elemento distintivo ha sido la movilización social. El Estado promotor del desarrollo social en esta zona es resultado de dicha movilización social, y su base social le ha dado la fuerza y la legitimidad necesarias para disminuir activamente las desigualdades en una sociedad tan heterogénea. El cambio se ha consolidado en un círculo virtuoso donde el Estado desarrollista incrementa la cohesión social y el capital humano por medio de sus acciones orientadas hacia la disminución de las desigualdades.

La tradición de movilización social en Kerala está muy relacionada con el movimiento nacionalista de independencia. Durante las primeras elecciones, el Partido Comunista desempeñó un papel fundamental en la mediación de conflictos y triunfó en la elección de 1957. Desde entonces el sistema democrático se ha consolidado y se ha dado una alternancia en el gobierno entre el Partido Comunista y su opositor, el Partido del Congreso, que es en realidad una coalición de partidos. La fuerza del Partido Comunista y su relación con las organizaciones de base crearon un contexto favorable para la formación de coaliciones entre sectores que tradicionalmente se encuentran divididos: en el sector agrícola, los pequeños propietarios de la tierra y los trabajadores agrícolas; en la industria, los sectores formal e informal. El gobierno comunista logró traducir las demandas sociales en metas comunes; también fue capaz de negociar agendas para la transición que contenían los intereses a corto plazo de diversos sectores sociales.

Desde la independencia de la India, la participación social ha desempeñado un papel muy importante en la consolidación de un Estado fuerte en Kerala y le ha dado la autonomía necesaria para no someterse a las demandas de las élites económicas tradicionales. De 
esta forma, el Estado ha sido capaz de adoptar las medidas que ha considerado necesarias para la transición y la consolidación del capitalismo, pero sin cargar los costos de éstas en los sectores más desfavorecidos. Heller hace la comparación con las experiencias de otras regiones del mundo. En Europa la burguesía fue el agente principal del cambio económico y social; en el Sudeste Asiático, el Estado fuerte y autoritario se ha encargado de él; en Kerala la clase trabajadora ha sido la responsable del cambio. La consolidación de la alternancia en el poder y las elecciones fuertemente competidas actúan como contrapesos de un Estado intervencionista y favorecen la consolidación de un sistema burocrático eficiente.

Hoy día la discusión en Kerala no versa sobre si se debe posponer el desarrollo social a costa del crecimiento económico. El debate y la imaginación política en Kerala se han orientado a reflexionar y discutir acerca de cómo mantener un crecimiento económico sostenido sin utilizar la estrategia basada en "exprimir a la fuerza de trabajo" (labor squeezing) como forma de acumulación o como principal ventaja comparativa en la economía de mercado. La presencia de un sector social organizado implica que la fuerza de trabajo no aceptará pagar desproporcionadamente los costos del crecimiento económico. Sin embargo la movilización social no es un obstáculo, sino una ventaja, cuando la organización sólida de los diversos sectores sociales se convierte en un espacio de negociación de las concesiones que cada clase social está dispuesta a hacer para lograr el objetivo común del desarrollo sostenido. Esto se complementa en el caso de Kerala con la presencia de un Estado legitimado que actúa como mediador y soluciona las diferencias en un "contexto institucional". En palabras de Heller, "lo que distingue a Kerala de otras regiones no es sólo el carácter del Estado — sus intereses específicos y sus características formales- sino principalmente el hecho de que sus instituciones y su autoridad han permeado las relaciones sociales" (Heller, 1999: 116). Y los diversos sectores sociales reconocen la legitimidad de las decisiones del Estado en la solución de conflictos tales como la definición de los salarios mínimos.

En México la cooptación ha sido la estrategia alternativa utilizada por el Estado para moldear las relaciones sociales. Los resultados negativos de dicha estrategia se pueden ver en el incremento de la pobreza, la caída del ingreso, la fragmentación de la sociedad mexicana (el incremento de la desigualdad social y económica); en resumen, pocos analistas discutirían ahora qué parte del fracaso de la estrategia 
de desarrollo de los últimos años es consecuencia de la falta de contrapesos a las acciones del Estado. En contraste con el corporatismo estatista de México, en Kerala hay un corporatismo democrático en el cual la sociedad mantiene su autonomía frente al Estado.

¿Qué podemos aprender de la experiencia de Kerala? Dos de las características distintivas de la experiencia de desarrollo del sudeste asiático son la baja desigualdad económica y social en la región y la elevada escolaridad. Kerala ha logrado recrear ambos aspectos; en ese sentido tal vez sea un ejemplo empírico de que el "desarrollo con rostro humano” es más que una buena intención. La institucionalización de los conflictos sociales por medio de la intervención del Estado puede sustituir el rol que desempeñaron el Estado autoritario y la fuerza de trabajo dócil en el contexto asiático.

¿Se puede repetir la experiencia de Kerala? Patrick Heller sostiene que el éxito de la experiencia de Kerala está basado en la acción de la sociedad organizada sobre la estructura del Estado y en la presencia de un Estado fuerte como mediador de los conflictos de clase. Sin embargo, ¿cómo se llega a una organización social autónoma consolidada? En el caso de Kerala, el Partido Comunista tuvo un papel central en el logro de acciones colectivas y en la creación de lazos horizontales entre los sectores sociales (por ejemplo, entre el trabajo formal e informal). ¿Quién puede promover tal cambio en México?, ¿quién puede generar los consensos necesarios para impulsar una estrategia de desarrollo incluyente? Frente a la escalada de la participación social ha surgido una clara fragmentación de intereses, metas y objetivos y - hasta hoy- al Estado mexicano no le ha interesado fomentar la participación social independiente ni fortalecer la autonomía estatal frente a las élites económicas. Como Jonathan Fox ${ }^{1}$ ha mencionado anteriormente, en el caso mexicano la fuerte tradición de participación no ha sido suficiente ni ha podido suprimir las iniciativas estatales. En México, el momento político de hoy abre espacios para los diversos actores políticos. En específico para el nuevo gobierno, la formación de consensos y la autonomía frente a los grupos más conservadores será uno de los principales retos a enfrentar, y es ahí donde la experiencia de Kerala tiene algo que enseñarnos.

${ }^{1}$ Jonathan Fox (1996), "How Does Civil Society Thicken? The Political Construction of Social Capital in Rural Mexico", World Development, vol. 24, núm. 6, pp. 1089-1104. 